\title{
Aqueous enzymatic extraction of oil from rice bran and its quality evaluation.
}

\author{
Duoxia $\mathrm{Xu}^{1}$, Jia $\mathrm{Hao}^{1}$, Zhenhua Wang ${ }^{1}$, Huanyue Yang ${ }^{1}$, Qianru Gao ${ }^{1}$, Ningning Ma ${ }^{1}$, \\ Junhai Wang ${ }^{1}$, Yinsong $\mathrm{Ma}^{1}$, and min Zhang ${ }^{1}$ \\ ${ }^{1}$ Affiliation not available
}

May 5, 2020

\begin{abstract}
Rice bran as a by-product of rice processing can be used to produce oil. The main objective of this study was to select appropriate enzymes for aqueous enzymatic extraction (AEE) and evaluated the quality of rice bran oil (RBO) obtained by $\mathrm{AEE}$ and solvent extraction (SE). In addition, the microstructure of rice bran before and after different extraction processes were also observed. The results showed that Alcalase $2.4 \mathrm{~L}$ was the most effective in releasing RBO. Moreover, iodine value and saponification value in the AEE-extracted oil (AEEO) were found to be higher than the SE-extracted oil (SEO). AEEO with lower acid value and peroxide value was considered to be a high quality and the content of wax and phospholipid in AEEO were lower, which could simplify the refining steps. Additionally, AEEO exhibited a higher content of unsaturated fatty acids $(76.31 \%)$, vitamin E $(1004.42 \mathrm{mg} / \mathrm{kg})$, sterols $(7749.44 \mathrm{mg} / 100 \mathrm{~g})$, squalene $(2962.56 \mathrm{mg} / \mathrm{kg})$ and oryzanol $(2.43 \%)$. In comparison to the SEO, AEEO was found to have lower crystallization and melting points. Scanning electron microscope (SEM) results showed the destruction of cell walls and the decrease of substances in the cell by AEE. In general, the results of this study showed improvement in the quality of the AEEO and provided necessary data support for green extraction of RBO in food industry.
\end{abstract}

\section{Introduction}

Rice bran, as a raw material for rice bran oil (RBO) extraction, is a by-product of rice processing, in which oil content can reach 12-22\% (Amarasinghe, Kumarasiri \& Gangodavilage, 2009; Pandey \& Shrivastava, 2018). RBO is a new type of edible oil with high nutritional value. Its fatty acid composition is reasonable and contains more than $80 \%$ oleic acid, linoleic acid and linolenic acid. In addition, RBO contains significant amounts of $\gamma$-oryzanol, tocopherols, squalene, phytosterol and other important bioactive substances, so it is known as "nutritional health oil" by nutritionists (Khoei \& Chekin, 2016; Trevisani Juchen, Nolasco Araujo, Hamerski, Corazza \& Pedersen Voll, 2019).

Current extraction methods of RBO used in oil industry mainly include cold pressing method, solvent extraction (SE) method and pre-pressed followed by SE. Cold pressing method can maintain the unique flavor of oils (Liu et al., 2011). However, this method has many problems, such as high residual oil rate, high cost, high labor intensity and power consumption, and easy to cause protein denaturation (Dun et al., 2019). SE method is often used in commercial RBO production, which is relatively efficient in oil production, and the residue of oil is low (Amarasinghe \& Gangodavilage, 2004), but there are also some shortcomings such as its toxicity, no renewability and easy to cause environmental pollution (Hanmoungjai, Pyle \& Niranjan, 2001). Pre-pressed treatment followed by SE method can obtain high oil extration yield. This process, however, has some problems in the protein structure leading to protein denaturation. Furthermore, n-hexane has been identified as an air pollutant that is emitted during extraction and recovery.

Compared with the other two methods, aqueous enzymatic extraction (AEE) process has the advantages of 
good oil quality, no chemical pollution, low energy consumption and good retention of protein, polysaccharide and other components. However, AEE has certain limitations. Due to the low solubility of oil in water, the efficiency of AEE is lower than that of SE. This disadvantage may be overcomed by using selected enzymes and optimizing process parameters (Mat Yusoff, Gordon, Ezeh \& Niranjan, 2016). AEE has become a new oil extraction technology for simultaneous extraction of oil and protein, polysaccharide and other components with broad application prospects.

It was reported that Sengupta \& Bhattacharyya (1996) used pectinase and cellulase for the first time to extract RBO by AEE combined with organic solvent. Hernandez, Rodriguez-Alegría, Gonzalez \& LopezMunguia (2000) obtained glucose, protein hydrolysate, RBO in three steps by adding glucoamylase and protease before extracting RBO with solvent. After that, Hanmoungjai, Pyle \& Niranjan (2002) focused on the extraction yield of RBO, protein and the level of reducing sugar in the enzymatic hydrolysis process, and finally indicated that Alcalase $2.4 \mathrm{~L}$ could significantly improve the yield of oil and protein, while the use of carbohydrase could improve the level of reducing sugar in the enzymatic hydrolysate. Although these papers have published on the extraction of RBO by AEE, no systematic studies have been conducted on the analysis of quality, thermal behavior and extraction mechanism of the extracted oil.

The objective of this study was to investigate the extraction of oil from rice bran using the AEE with different enzymes (Celluclast 1.5L, Hemicellulase, Pectinex Ultra SP-L, Viscozyme L and Alcalase 2.4L) and selected appropriate enzymes for AEE. The physicochemical properties, fatty acid compositions, bioactive compounds and thermal behavior of AEE-extracted oil (AEEO) were evaluated and compared with those of Soxhlet-extracted oil (SEO). In addition, the microstructure of rice bran before and after different extraction processes were observed, and the mechanism of rice bran oil by enzyme extraction was clarified.

\section{Materials and methods}

\subsection{Materials}

Expanded rice bran were purchased from Fushi Rice Industry Ltd, Kiamusze, Heilongjiang Province, China. In order to prevent rancidity, the raw materials were stored in the refrigerator at -20 . Celluclast 1.5L, Pectinex Ultra SP-L, Viscozyme L and Alcalase 2.4L were purchased from Novozymes Bagsvaerd (Denmark). Hemicellulase and the standard of tocopherols, tocotrienols, sterols and squalene were obtained from SigmaAldrich Co. (Steinheim, Germany). Fatty acid methyl esters (FAMEs) standards were obtained from the AccuStandard (New Haven, CT, USA). Additionally, all other chemicals were of analytical grade.

\subsection{Aqueous enzymatic extraction (AEE) process}

Fresh rice bran was screened through a 40 -mesh sieve (450 $\mu \mathrm{m}$ aperture size), the powders were sealed in plastic containers and stored in a refrigerator at 4 for 24 hours before use. The ground rice bran was mixed with distilled water at a ratio of 1:6 w/v using a beaker. The mixture was subjected to boiling for 5 min at 90 and allowed to cool down to room temperature (Mat Yusoff et al., 2016). The $\mathrm{pH}$ of the mixture was adjusted to the optimum $\mathrm{pH}$ of enzyme with $2 \mathrm{M} \mathrm{NaOH}$ and $2 \mathrm{M} \mathrm{HCl}$. Then $2 \%(\mathrm{w} / \mathrm{w}$ ) of enzyme (Celluclast 1.5L, Hemicellulase, Pectinex Ultra SP-L, Viscozyme L, Alcalase 2.4L) was added to the mixture, respectively. The samples were incubated at the optimum temperatures $(50,50,50,45,60)$ of various enzymes for 120 min followed by centrifugation (Hexi Instrument Equipment Co. Ltd., H/T 16MM, Hunan, China) at $10000 \mathrm{rpm}, 30$ for $20 \mathrm{~min}$. After centrifugation, the enzymatic hydrolysate was divided into four phases: oil phase, creaming phase, aqueous phase and residue phase. The top oil phase was withdrawn by suction tube, the creaming phase was separated and demulsified with ethanol solution and further centrifuged to obtain residual oil. The free oil was combined and used for analysis. Then the residue phase was baked at 60 for 4 hours and analysed for residual oil according to the 2.3 method. The extraction yield was calculated according to the method reported by Hanmoungjai et al. (2002). In addition to individual carbohydrase, the combined effect of each carbohydrase with Alcalase 2.4L on the extraction of RBO was also studied. The rice bran was first incubated with $1 \%(\mathrm{w} / \mathrm{w})$ carbohydrase for $1 \mathrm{~h}$ and then with $1 \%(\mathrm{w} / \mathrm{w})$ Alcalase $2.4 \mathrm{~L}$ for another hour. All other treatments were identical to single enzyme treatments. Control samples underwent the same extraction process except for the enzyme addition. 


\subsection{Soxhlet extraction (SE) process}

Rice bran was placed into a cellulose paper cone and extracted for $6 \mathrm{~h}$ in a Soxhlet extractor at 90 with n-hexane according to the Soxhlet standard extraction method (AOAC, 1997). The oil was then recovered by evaporating off the solvent at 50 under reduced pressure using a rotary evaporator Model RE-2000A (Yarong Biochemical Instrument Factory, Shanghai, China) and residual solvent was removed by flushing with $99.99 \%$ nitrogen. This technique produced $18.45 \pm 0.25 \mathrm{~g}$ of oil per $100 \mathrm{~g}$ of rice bran, which was set as $100 \%$ oil recovery for comparison. The recovered oil was stored at 4 until use.

\subsection{Physicochemical properties}

AOCS Standard Methods (1997) were used for the determination of the acid value (method Cd 3d-63), iodine value (method $\mathrm{Cd} 1-25$ ), saponification value (method $\mathrm{Cd} 3-25)$ and peroxide value (method $\mathrm{Cd}$ 8-53) of AEEO and SEO.

The wax and phospholipid content of RBO were measured according to the method reported by Pandey et al. (2018). Specifically, wax content in RBO was measured as acetone insoluble fraction and phospholipid content of RBO was measured by the Vanadomolybdate method.

The colour parameters of oil samples were measured using chroma meter CR-400 (Konica Minolta Sensing, Inc., Osaka, Japan). Before using the chroma meter, it was necessary to correct. A certain amount of oil samples were taken in the cuvette, then used the chroma meter to irradiation. The data of L-value, a-value, b-value and colour difference $\left({ }^{E}\right)$ wererecorded.

\subsection{GC-MS analysis of fatty acid compositions}

GC-MS was used for fatty acid composition of RBO analysis. The sample pretreatment was carried out according to the method reported by Zhang et al. (2010). GC-MS analysis of FAMEs according to the method of China National Standard GB 5009.168-2016. The analysis were performed by a QP2010 gas chromatography/mass spectrometer (Shimadzu, Kyoto, Japan), equipped with a TR-WAXMS capillary column $(30 \mathrm{~m} \times 0.25 \mathrm{~mm} \times 0.25 \mu \mathrm{m})$. The specific operating conditions were as follows: injector temperature 250 ; carrier gas was high purity nitrogen; flow rate $1 \mathrm{~mL} / \mathrm{min}$; split ratio 1:10; the column temperature from 80 to 210 at the rate of $15 / \mathrm{min}$; finally increased to 240 at the rate of $2 / \mathrm{min}$; ion source temperature 200 ; detector temperature 240 ; mass range $40-500 \mathrm{~m} / \mathrm{z}$. The components of oil were determined by comparison of their retention indices with those of authentic standards of FAMEs.

\subsection{Bioactive compounds analysis}

\subsubsection{Chromatographic analysis of vitamin $E$}

The content of vitamin E in oil samples was determined by HPLC. Oil was diluted with n-heptane and analyzed using Agilent Technologies 1260-HPLC apparatus (Santa Clara, CA, USA) equipped with a fluorescent detector from the same manufacturer. Separation was carried on a Venusil XBP Silica column $(4.6 \times 250$ $\mathrm{mm} \times 5 \mu \mathrm{m})$. The mobile phase was a $3.85 \%$ tetrahydrofuran in n-heptane solution with a flow rate of 1 $\mathrm{mL} / \mathrm{min}$. The fluorescence detector was set at $\lambda_{\text {excitation }}=294 \mathrm{~nm}$ and $\lambda_{\text {emission }}=330 \mathrm{~nm}$.

\subsubsection{Gas chromatography analysis of sterols}

According to the modified method of Nyam, Tan, Che Man, Lai \& Long (2009), the content of sterols was determined by the gas chromatography. Oil samples and $5 \alpha$-cholestane solution were refluxed with ethanolic potassium hydroxide solution for $80 \mathrm{~min}$. The unsaponifiables were first extracted with diethylether for three times, the ether layers were washed twice with $0.5 \mathrm{M} \mathrm{KOH}$ and deionized water, and then dried with anhydrous sodium sulphate. The extract was evaporated in a vacuum evaporator at $25{ }^{\circ} \mathrm{C} . \mathrm{N}$, O-Bis (trimethylsilyl) trifluoroacetamide (BSTFA) with $1 \%$ trimethylchlorosilane (TMCS) was added to the dry extracts, and the mixtures were heated at $60{ }^{\circ} \mathrm{C}$ for $60 \mathrm{~min}$. The analysis was carried out using the GC-2010 PLUS (Shimadzu, Kyoto, Japan). Sterols were separated on a HP-1 capillary column $(25 \mathrm{~m} \times 0.32 \mathrm{~mm} \times$ 
$0.17 \mu \mathrm{m}$; Agilent, Santa Clara, CA, USA). The temperatures were as follows: injector $250{ }^{\circ} \mathrm{C}$, column 190 ${ }^{\circ} \mathrm{C}$ increased to $230{ }^{\circ} \mathrm{C}$ at $20{ }^{\circ} \mathrm{C} / \mathrm{min}$, then to $255{ }^{\circ} \mathrm{C}$ at $40{ }^{\circ} \mathrm{C} / \mathrm{min}$, and maintained for $17 \mathrm{~min}$.

\subsubsection{Gas chromatography analysis of squalene}

The content of squalene was determined by the gas chromatography. $0.2-2 \mathrm{~g}$ oil samples and $300 \mu \mathrm{L}$ squalane internal standard solution were saponified with $50 \mathrm{~mL}$ ethanolic potassium hydroxide solution at $80{ }^{\circ} \mathrm{C}$ for $50 \mathrm{~min}$, then were transferred to a separatory funnel containing deionized water. The saponification solution was extracted three times with n-hexane, and the extract was combined. The organic phase was washed to neutral by adding $25 \mathrm{~mL}$ ethanol solution. Then the residual water was removed by anhydrous sodium sulfate and the solvent was evaporated in a vacuum evaporator at $40{ }^{\circ} \mathrm{C}$. The analysis was carried out using the GC-2010 PLUS (Shimadzu, Kyoto, Japan) and squalene was separated on a DB-5 capillary column (25 $\mathrm{m} \times 0.32 \mathrm{~mm} \times 0.17 \mu \mathrm{m} ;$ Agilent, Santa Clara, CA, USA). The operating conditions were as follows: split ratio 1:10; injector $250{ }^{\circ} \mathrm{C}$; column $160{ }^{\circ} \mathrm{C}$ increased to $220{ }^{\circ} \mathrm{C}$ at $15{ }^{\circ} \mathrm{C} / \mathrm{min}$, increased to $280{ }^{\circ} \mathrm{C}$ at $5{ }^{\circ} \mathrm{C} / \mathrm{min}$, maintained for $20 \mathrm{~min}$, and finally to $300{ }^{\circ} \mathrm{C}$ at $5{ }^{\circ} \mathrm{C} / \mathrm{min}$ for $2 \mathrm{~min}$. Squalane was identified by standard substances and the contents were determined by the concentration of internal standard.

\subsubsection{Determination of the contents of oryzanol}

According to the method of China Grain Sector Standard LS/T 6121.1-2017, the oryzanol content in RBO was calculated and analyzed by UV-VIS spectrophotometer (UV2800-A, UNICO instruments Co. Ltd., Shanghai, China). $0.02 \mathrm{~g}$ oils were weighed and diluted to $25 \mathrm{~mL}$ with n-heptane. The absorbance of the solution was measured at $315 \mathrm{~nm}$ with n-heptane as blank. The measured absorbance should be between $0.2-0.8$, beyond which further dilution was required. The content of oryzanol was calculated according to the formula given below, and the specific extinction coefficient of oryzanol was known $(359 \mathrm{~g} / 100 \mathrm{~mL})$.

Oryzanol $(\%)=\frac{\mathrm{A} \times \mathrm{N} \times 25}{\mathrm{~m}(\mathrm{~g}) \times 359} \frac{\mathrm{A} \quad \mathrm{N} \quad 25}{\mathrm{~m}(\mathrm{~g}) 359}$

where $\mathrm{A}, \mathrm{N}, \mathrm{m}$, were the absorbance of samples, dilution factor after samples volume determination $(\mathrm{N}=1$ if not diluted) and weight of samples, respectively.

\subsection{Thermal behavior analysis}

Thermal behavior of RBO was analyzed following the method given by Samaram, Mirhosseini, Tan \& Ghazali (2014). The thermal properties of the RBO were studied by differential scanning calorimetry (DSC) using a DSC-60A (Shimadzu, Kyoto, Japan). The purge gas used was $99.99 \%$ nitrogen with a pressure of $0.5 \mathrm{MPa}$ and a flow rate of $100 \mathrm{~mL} / \mathrm{min} .5-7 \mathrm{mg}$ of the RBO was weighed in a aluminum pan, heated to 60 and held for $5 \mathrm{~min}$, then cooled from 60 to -50 by a rate of $10 / \mathrm{min}$ with 5 min holding time, finally heated from -50 to 60 at a rate of $10 / \mathrm{min}$, and maintained for $5 \mathrm{~min}$.

\subsection{Scanning electron micrographs (SEM)}

The morphological changes in bran before and after extraction were studied by a Hitachi S-4800 scanning electron microscope system (Hitachi Corporation, Japan). Samples were dried at 105 for $24 \mathrm{~h}$, then were fixed on a specimen holder with an aluminium tape and sputter-coated with gold. The images were obtained under vacuum with an acceleration tension of $15 \mathrm{kV}$.

\subsection{Statistical analysis}

Results were expressed as means +- standard deviations. The data were statistical analysis using the software package SPSS 17.0 for Windows (SPSS Inc., Chicago, IL). Differences between means were determined by analysis of variance (ANOVA) with Duncan multiple range test. Differences were considered statistically significant at $P<0.05$. All tests were performed in triplicate.

\section{Results and discussion}

\subsection{Selection of appropriate enzyme for AEE}


Fig. 1 showed the effect of five different enzymes (Celluclast 1.5L, Hemicellulase, Pectinex Ultra SP-L, Viscozyme $\mathrm{L}$ and Alcalase $2.4 \mathrm{~L}$ ) on RBO extraction yields. It could be observed from Fig. 1a that more RBO was extracted using hydrolytic enzymes (28.59-50.37\%) compared with the control (21.30-40.12\%). Alcalase $2.4 \mathrm{~L}$ was found to be the optimum enzyme obtaining the highest RBO yields with $50.37 \%$. The efficiency of Alcalase 2.4L for RBO extraction was consistent with the results of Hanmoungjai et al. (2002). Indeed, protease treatment can hydrolyze proteins into peptides, leading to effective dissolution and hydrolysis of proteins, then break down the protein networks of cotyledon cells and protein based membranes surrounding the lipid bodies, thereby liberating more oils (Jiao et al., 2014; Latif \& Anwar, 2011). It was also found that the oil extraction yields of control at $\mathrm{pH} 9.0$ was significantly higher than that of the carbohydrase treated rice bran. This might be due to the increased solubility of proteins under alkaline conditions and saponification of available free fatty acids, which improved the separation efficiency of oil bodies from their original location at high $\mathrm{pH}$ and low surface tension (Amarasinghe et al., 2009).

The effect of the combination of each carbohydrase with Alcalase $2.4 \mathrm{~L}$ on oil yields was shown in Fig. 1b. It exhibited that the combination of carbohydrases and protease did not significantly increase the extraction yields of RBO. The use of cellulose, pectinase and other carbohydrase can hydrolyze cellulose, hemicellulose, pectin and other components forming cell wall thus breaking down the structural integrity of the cell walls and improving the oil extraction yields. However, the rice bran material selected in this study had been expanded, which could damage the cell wall to a certain extent, therefore, the carbohydrases had little effect on the release and extraction of RBO as shown in the result.

\subsection{Physicochemical properties of extracted RBO}

The physicochemical properties of AEE-extracted oil (AEEO) and SE-extracted oil (SEO) were listed in Table 1. Acid value and peroxide value, respectively, indicated the oxidation and rancidity of RBO and oil samples with low acid value and peroxide value were considered to be a high quality. The acid value in the AEEO were found to be slightly lower than the SEO, but the difference were not significant $(p>0.05)$. Moreover, the PV of AEEO $(8.15+-0.44 \mathrm{mmol} / \mathrm{kg})$ was found to be significantly $(p<0.05)$ lower than 8.80 +- $0.00 \mathrm{mmol} / \mathrm{kg}$ for SEO. These values are slightly different from those reported by Phan, Junyusen, Liplap \& Junyusen (2018), which may be due to climate conditions and different cultivars of rice bran. Additionally, iodine value $\left(106.31+-0.44 \mathrm{~g} \mathrm{I}_{2} / 100 \mathrm{~g}\right.$ oil $)$ in the AEEO was found to be higher than the SEO $(102.22+-$ $0.56 \mathrm{~g} \mathrm{I}_{2} / 100 \mathrm{~g}$ oil) which can be due to a higher content of unsaturated fatty acids in the AEEO. The saponification value of SEO was significantly $(p<0.05)$ lower than AEEO and the values were similar to those reported by Amarasinghe et al. (2009) and Sengupta et al. (1996).

Wax content of AEEO was found to be significantly less than the SEO. Wax in RBO seriously affects the quality of RBO. However, as an important by-product of RBO refining process, rice bran wax is rich in octacosanol. Octacosanol has been widely used in various food production due to the function of lowering blood lipid or cholesterol (Chen et al., 2007). A significantly $(p<0.05)$ higher concentration of phospholipids was determined in the SEO compared with the AEEO. According to Balachandran, Mayamol, Thomas, Sukumar, Sundaresan \& Arumughan (2008), the phospholipid content in RBO extracted with n-hexane ranged from $1 \%$ to $5 \%$, which was agreement with the results of this study. While, no phospholipids were detected in RBO extracted by AEE. The result was consistent with the report of Rovaris et al. (2012) that more than $90 \%$ lipids existed in the residue phase and the rest in the aqueous phase during the enzymatic extraction of soybean oil. Because of the presence of phospholipids and effective emulsifiers such as lecithin, oils are emulsified and not easy to be separated from raw materials. Phospholipids have a polar phosphate group attached to a lipid group by electrostatic forces and hydrogen bonds, which can be transferred to the oil when the polar solvent, able to break these bonds and release them, is used as extraction medium (Capellini, Giacomini, Cuevas \& Rodrigues, 2017). It can be concluded that the contents of wax and phospholipid in AEEO was low, which can simplify the following refining steps.

It was also found that the L-value and b-value of AEEO were higher than SEO. It indicated that AEEO were more yellow and lighter-coloured than SEO. It can be attributed to that the organic solvent extracted pigments such as carotenes and chlorophylls from the bran. Consequently, the results of physicochemical 
properties showed that the quality of AEEO was better than that of SEO.

\subsection{Fatty acid compositions}

As shown in Table 2, fourteen major fatty acid components were detected and identified, including eight saturated fatty acids, four monounsaturated fatty acids and two polyunsaturated fatty acids. Comparing the composition of AEEO and SEO fatty acids, it was found that there were some differences presented in fatty acid contents, while no obvious difference in their types was detected. The results showed that the extraction method had no significant effect on fatty acid composition of oils, which was in agreement with other reports (Jiao et al., 2014; Li et al., 2013). The contents of fatty acid obtained were different from the values obtained by Trevisani Juchen et al. (2019). The difference in fatty acid contents might be attributed to the cultivars, planting regions, climate conditions, and the posttreatment process (Liu et al., 2019).

It could be observed that the preponderant fatty acid in RBO was linoleic acid (38.26\%-38.84\%), oleic acid (33.83\%-34.31\%), followed by palmitic acid (19.17\%-19.87\%). It also could be seen that the content of unsaturated fatty acids accounting for about $75 \%$ of total fatty acids in AEEO and SEO. Moreover, the contents of monounsaturated fatty acids and polyunsaturated fatty acids in AEEO were much higher than that of SEO. It was likely because the relatively mild extraction conditions of AEE was not easy to cause the oxidation and decomposition of unsaturated fatty acids. According to the literature, the oil contains a high level of monounsaturated fatty acid, which has a great potential to produce biodiesel (Lovato, Pelegrini, Rodrigues, Braz De Oliveira \& Piloto Ferreira, 2014). The high proportion of linoleic and linolenic acids were precursors of polyunsaturated fatty acids from the omega- 3 and omega- 6 series and were essential for human health and disease prevention, which indicated their potential development prospects in health products and pharmaceutical industries (Chen, Luo, Qi \& Wan, 2014), but also reduced oil stability and shelf life (Haiyan, Bedgood, Bishop, Prenzler \& Robards, 2007). Therefore, compared with SE, AEE can reduce costs and green production, while AEEO also has health benefits.

\subsubsection{Vitamin E contents}

$\mathrm{VE}$ is a recognized antioxidant, mainly $\alpha / \gamma$-tocopherol and tocotrienol in RBO (Capellini et al., 2017). In this experiment, the total amount of vitamin $E$ was expressed as the sum of $\alpha$ tocopherol, $\alpha$-tocotrienol, $\gamma$-tocopherol and $\gamma$-tocotrienol. As shown in Table 3, the vitamin E content in RBO ranged from 839.15 to $1004.42 \mathrm{mg} / \mathrm{kg}$, which was similar to that of Zigoneanu, Williams, Xu \& Sabliov (2008). A significantly $(p<0.05)$ higher concentration of total vitamin $\mathrm{E}$ was determined in the AEEO as against the SEO. The higher concentration of vitamin $\mathrm{E}$ in the AEEO could improve its oxidative stability. It also could be seen that the content of tocotrienol ranged from 547.02 to $643.67 \mathrm{mg} / \mathrm{kg}$, accounting for about $60 \%$ of total vitamin $\mathrm{E}$ in RBO and the tocotrienol content in AEEO was significantly $(p<0.05)$ higher than that of SEO. Tocotrienols had more significant physiological functions than tocopherol in antioxidant activity, cholesterol and blood lipid reduction (Qureshi et al., 1991). Comparison of AEEO and SEO showed significant $(p<0.05)$ difference of $\alpha$-tocopherol contents which were $315.87 \mathrm{mg} / \mathrm{kg}$ and $261.13 \mathrm{mg} / \mathrm{kg}$. Karmowski, Hintze, Kschonsek, Killenberg \& Böhm (2015) confirmed that the antioxidant capacity of $\alpha$-tocopherol was slightly lower than that of $\alpha$-tocotrienol. It can be seen that AEEO with higher natural antioxidant is an important nutritional and healthy oil, and its development and utilization prospects are very broad.

\subsubsection{Sterols contents}

The content and composition of phytosterols in RBO extracted using various methods were listed in Table 3. It was found that the levels of phytosterols in RBO obtained by AEE was much higher compared with that of SEO. It was in agreement with Konopka, Roszkowska, Czaplicki \& Tańska (2016) who reported that higher phytosterols content in the enzyme-extracted oil. While, it was different from the results of Nyam et al. (2009) that the Kalahari melon seed oil extracted by organic solvents contained higher sterols contents. As could be seen in Table 3, the predominant sterols in RBO were $\beta$-sitosterol (50\% of total sterols), followed by campesterol, stigmastanol and stigmasterol. It indicated that enzymatic treatment can release more 
antioxidant compounds from rice bran due to the hydrolysis of cell walls. In addition, enzymatic hydrolysis can reduce the degree of interaction between antioxidants and proteins, polysaccharides and pectins in the bran and promote their release into oils (Fang, Du, Luo \& Jin, 2015). The lower content of unsaponifiable compounds in SEO might be due to the low polarity of n-hexane.

\subsubsection{Squalene contents}

Squalene is a highly unsaturated aliphatic hydrocarbon $\left(\mathrm{C}_{30} \mathrm{H}_{50}\right)$, which is widely found in olive oil, soybean oil and peanut oil (Chanioti \& Tzia, 2019). Previous studies have shown that squalene has natural antioxidant activity, which makes it widely used in cosmetics. However, phenols and tocopherols are the main antioxidants in oils, which makes the antioxidant activity of squalene less obvious (Psomiadou \& Tsimidou, 1999). Comparison of AEEO and SEO showed significant $(p<0.05)$ differences of squalene contents which were $2962.56 \mathrm{mg} / \mathrm{kg}$ and $2479.56 \mathrm{mg} / \mathrm{kg}$, respectively. It indicated that AEE promoted the release of squalene compared with SE. The contents of squalene obtained by extraction were much less compared with that by cold pressing (3189 mg/kg) (Pokkanta, Sookwong, Tanang, Setchaiyan, Boontakham \& Mahatheeranont, 2019). It illustrated that the content of squalene in crude oils depended on the different extraction methods.

\subsubsection{Oryzanol contents}

Rice bran is one of the most abundant sources of oryzanol. RBO contains about $0.9-2.9 \%$ oryzanol which can vary greatly according to the origin of the rice bran (Arab, Alemzadeh \& Maghsoudi, 2011). Oryzanol is a mixture of esters of ferulic acid with sterols and triterpene alcohols, and has similar antioxidant activity as vitamin E (Lloyd, Siebenmorgen \& Beers, 2007). In Table 3, the content of oryzanol in AEEO was significantly higher $(p<0.05)$ than in SEO, which can be attributed to the degradation of oryzanol caused by the increase of temperature and the prolongation of SE treatment time.

\subsection{Thermal behavior of AEEO and SEO}

DSC is to determine the thermal behavior of oils during heating or cooling and it provides another method for studying the chemical composition of oils. The crystallization and melting curves of the AEEO and SEO were shown in Fig. 2 and their corresponding transition temperatures were also given.

In Fig. 2a, the crystallization curves of RBO extracted by Alcalase $2.4 \mathrm{~L}$ and n-hexane were represented. The cooling curve of AEEO and SEO exhibited three exothermic peaks, with a major peak $\left(\mathrm{a}_{2}, \mathrm{~b}_{2}\right)$ and two small shoulder peaks $\left(a_{1}, b_{1}\right)$ and $\left(a_{3}, b_{3}\right)$. It could be clearly seen that the points of crystallization peaks of the two extraction methods were obviously different. The initial crystallization peaks of AEEO and SEO were 30.93 and 33.70 , respectively. Compared with the SEO, the crystallization point of AEEO was lower. The various of crystallization peaks might be due to the different extraction methods, which could influence the degree of saturation in RBO (Tan, Chong, Hamzah \& Ghazali, 2018). Generally, each kind of oil has unique characteristic of fatty acids and triacylglycerol (TAG) profiles and the thermal transition of lipids is affected by the compositional changes of the degree of saturation and fatty acid chain length. The crystallization peaks of oils with high levels of saturated fatty acids and tri-saturated TAGs would be at a relatively high temperature (Mohammadpour, Sadrameli, Eslami \& Asoodeh, 2019).

The melting curves of RBO extracted by Alcalase $2.4 \mathrm{~L}$ and $n$-hexane were represented in Fig. $2 \mathrm{~b}$. It was found that SEO displayed one peak $\left(b_{1}\right)$ at low-melting region $(<0)$ and the other peak $\left(b_{2}\right)$ at highmelting region $(>0)$. However, this phenomenon was not observed in the melting curves of AEEO and all the melting peaks of AEEO were located in the low-melting region. Results showed that the melting

behavior of RBO was significantly related to the extraction method. As discussed, the possible reason of these differences might be the variations in the proportional distributions of the identified fatty acid and TAG components. It might be due to the saturated compounds of SEO were slightly higher than AEEO. Therefore, higher temperatures were needed to melt SEO completely.

\subsection{Microstructural analysis}

To better understand the influence of different extraction methods on the characteristics of RBO, microstruc- 
ture of native and samples after extraction were investigated by SEM. The images showed that the internal tissue of the rice bran seems to undergo a process of destructing and restructuring. In Fig. 3a, natural rice bran had a relatively complete structure, regular or dense shape and smooth surface, meanwhile, the intact oil cells on the surface of bran tissues before extraction were observed. Fig. 3b showed the expansion process caused the disruption of cell walls and loose cell arrangement of expanded rice bran, making conventional extraction or enzymatic extraction more accessible to organelle. After AEE, the oil was almost extracted together with aleurone grains and the substances in the cell gradually were decreased, therefore, the structure of rice bran cell was further destroyed (Fig. 3c). In Fig. 3d, the surface of rice bran treated with n-hexane became more fragmented, dried and cracked, and some lipids and starches were dragged away (Alcázaralay, Cardenastoro, Santos \& Meireles, 2015). In the process of SE, the chemical affinity between organic solvent and oils affected the mass transfer process which caused a high oil extraction yield, but it could also damage the protein and starch in the extraction process. The process of enzymatic extraction was based on the insolubility of oils in water and the efficiency was lower than that of SE. However, AEE could simultaneously separate solid phase (mainly starches and proteins) and an oil phase, so the development of these by-products could also make full use of rice bran.

\section{Conclusion}

In the present work, AEE process proved to be effective in extracting RBO. Alcalase 2.4L was found to give higher oil yields than Celluclast 1.5L, Hemicellulase, Pectinex Ultra SP-L, Viscozyme L. Comparisons of the physicochemical characteristics of AEEO with those of SEO revealed that different extraction methods had influence on the quality parameters of RBO. Briefly, iodine value, saponification value in the AEEO were found to be higher than SEO. AEEO had lower acid value and peroxide value which was considered to be a high quality oil. The content of wax and phospholipid in AEEO was lower, which could simplify the refining steps. In addition, GC-MS results showed that AEE increased the amounts of unsaturated fatty acids compared with SE. A comparison of the content of bioactive compounds showed that RBO extracted by the AEE was more abundant in vitamin E, sterols, squalene and oryzanol. DSC results indicated that the different methods used for oil extraction caused the variations in the melting and crystallization behaviour of RBO. In comparison to the SEO, AEEO were found to have lower crystallization and melting points. Moreover, SEM results demonstrated that the destruction of cell walls and the decrease of substances in the cell by AEE. These results suggested that AEE offers an efficient, environment friendly and easy procedure of RBO extraction and the oil produced by this emerging method can be used as high-quality edible oil in food industry.

\section{Acknowledgements}

This research was supported by the 13th Five-Year the State Key Development Program (2018YFD0401100), National Natural Science Foundation of China (31771976), Support Project of High-level Teachers in Beijing Municipal Universities in the Period of 13th Five-year Plan (CIT \& TCD201804018), Construction of Service Capability of Scientific and Technological Innovation (PXM2019_014213_000010, PXM2018_014213_000033, PXM2018_014213_000014, PXM2018_014213_000041, 19005857058), Cultivation and Development of Innovation Base (Z171100002217019), School Level Cultivation Fund of Beijing Technology and Business University for Distinguished and Excellent Young Scholars (BTBUYP2020), Beijing Key Laboratory of the Innovative Development of Functional Staple and the Nutritional Intervention for Chronic Disease.

\section{References}

Alcazaralay, S. C., Cardenastoro, F. P., Santos, D. T., \& Meireles, M. A. A. (2015). Study of an extraction process as the pretreatment step for sugar production from acid hydrolysis. Food and Public Health, 2015 (52), 47-55.

Amarasinghe, B. M. W. P., Kumarasiri, M. P. M., \& Gangodavilage, N. C. (2009). Effect of method of stabilization on aqueous extraction of rice bran oil.Food and Bioproducts Processing , 87 (2), 108-114.

Amarasinghe, B. M. W. P., \& Gangodavilage, N. C. (2004). Rice Bran Oil Extraction in Sri Lanka: Data 
for Process Equipment Design. Food and Bioproducts Processing, 82 (1), 54-59.

Arab, F., Alemzadeh, I., \& Maghsoudi, V. (2011). Determination of antioxidant component and activity of rice bran extract. Scientia Iranica, 18 (6), 1402-1406.

Balachandran, C., Mayamol, P. N., Thomas, S., Sukumar, D., Sundaresan, A., \& Arumughan, C. (2008). An ecofriendly approach to process rice bran for high quality rice bran oil using supercritical carbon dioxide for nutraceutical applications.Bioresource Technology ,99 (8), 2905-2912.

Capellini, M. C., Giacomini, V., Cuevas, M. S., \& Rodrigues, C. E. C. (2017). Rice bran oil extraction using alcoholic solvents: Physicochemical characterization of oil and protein fraction functionality.Industrial Crops and Products , 104, 133-143.

Chanioti, S., \& Tzia, C. (2019). Evaluation of ultrasound assisted and conventional methods for production of olive pomace oil enriched in sterols and squalene. LWT Food Sci. Technol, 99 , 209-216.

Chen, F., Wang, Z., Zhao, G., Liao, X., Cai, T., Guo, L., \& Hu, X. (2007). Purification process of octacosanol extracts from rice bran wax by molecular distillation. Journal of Food Engineering ,79 (1), 63-68.

Chen, X., Luo, Y., Qi, B., \& Wan, Y. (2014). Simultaneous extraction of oil and soy isoflavones from soy sauce residue using ultrasonic-assisted two-phase solvent extraction technology.Separation and Purification Technology , 128, 72-79.

Dun, Q., Yao, L., Deng, Z., Li, H., Li, J., Fan, Y., \& Zhang, B. (2019). Effects of hot and cold-pressed processes on volatile compounds of peanut oil and corresponding analysis of characteristic flavor components. LWT Food Sci. Technol, 112, 107648.

Fang, X., Du, M., Luo, F., \& Jin, Y. (2015). Physicochemical Properties and Lipid Composition of Camellia Seed Oil (Camellia oleiferaAbel.) Extracted Using Different Methods.Food Science and Technology Research , 21 (6), 779-785.

Haiyan, Z., Bedgood, D. R., Bishop, A. G., Prenzler, P. D., \& Robards, K. (2007). Endogenous biophenol, fatty acid and volatile profiles of selected oils. Food Chemistry, 100 (4), 1544-1551.

Hanmoungjai, P., Pyle, D. L., \& Niranjan, K. (2001). Enzymatic process for extracting oil and protein from rice bran. Journal of the American Oil Chemists' Society , 78 (8), 817-821.

Hanmoungjai, P., Pyle, D. L., \& Niranjan, K. (2002). Enzyme-assisted water-extraction of oil and protein from rice bran. Journal of Chemical Technology and Biotechnology , 77 (7), 771-776.

Hernandez, N., Rodriguez-Alegria, M. E., Gonzalez, F., \& Lopez-Munguia, A. (2000). Enzymatic treatment of rice bran to improve processing.Journal of the American Oil Chemists' Society, 77 (2), 177-180.

Jiao, J., Li, Z., Gai, Q., Li, X., Wei, F., Fu, Y., \& Ma, W. (2014). Microwave-assisted aqueous enzymatic extraction of oil from pumpkin seeds and evaluation of its physicochemical properties, fatty acid compositions and antioxidant activities. Food Chemistry ,147, 17-24.

Karmowski, J., Hintze, V., Kschonsek, J., Killenberg, M., \& Bohm, V. (2015). Antioxidant activities of tocopherols/tocotrienols and lipophilic antioxidant capacity of wheat, vegetable oils, milk and milk cream by using photochemiluminescence. Food Chemistry , 175, 593-600.

Khoei, M., \& Chekin, F. (2016). The ultrasound-assisted aqueous extraction of rice bran oil. Food Chemistry , $194,503-507$.

Konopka, I., Roszkowska, B., Czaplicki, S., \& Tańska, M. (2016). Optimization of Pumpkin Oil Recovery by Using Aqueous Enzymatic Extraction and Comparison of the Quality of the Obtained Oil with the Quality of Cold-Pressed Oil.Food Technology and Biotechnology , 54 (4), 413.

Latif, S., \& Anwar, F. (2011). Aqueous enzymatic sesame oil and protein extraction. Food Chemistry , 125 (2), 679-684. 
Li, J., Zu, Y., Luo, M., Gu, C., Zhao, C., Efferth, T., \& Fu, Y. (2013). Aqueous enzymatic process assisted by microwave extraction of oil from yellow horn (Xanthoceras sorbifolia Bunge.) seed kernels and its quality evaluation. Food Chemistry, 138 (4), 2152-2158.

Liu, Z., Gui, M., Xu, T., Zhang, L., Kong, L., Qin, L., \& Zou, Z. (2019). Efficient aqueous enzymaticultrasonication extraction of oil from Sapindus mukorossi seed kernels. Industrial Crops and Products , 134 , 124-133.

Liu, X., Jin, Q., Liu, Y., Huang, J., Wang, X., Mao, W., \& Wang, S. (2011). Changes in volatile compounds of peanut oil during the roasting process for production of aromatic roasted peanut oil. Journal of Food Science, 76 (3), C404-C412.

Lloyd, B. J., Siebenmorgen, T. J., \& Beers, K. W. (2007). Effects of commercial processing on antioxidants found in rice bran. Cereal Chemistry, 77 (5), 551-555.

Lovato, L., Pelegrini, B. L., Rodrigues, J., Braz De Oliveira, A. J., \& Piloto Ferreira, I. C. (2014). Seed oil of Sapindus saponaria L. (Sapindaceae) as potential C16 to C22 fatty acids resource. Biomass and Bioenergy , $60,247-251$.

Mat Yusoff, M., Gordon, M. H., Ezeh, O., \& Niranjan, K. (2016). Aqueous enzymatic extraction of Moringa oleifera oil. Food Chemistry,211, 400-408.

Mohammadpour, H., Sadrameli, S. M., Eslami, F., \& Asoodeh, A. (2019). Optimization of ultrasoundassisted extraction of Moringa peregrina oil with response surface methodology and comparison with Soxhlet method.Industrial Crops and Products , 131, 106-116.

Nyam, K. L., Tan, C. P., Che Man, Y. B., Lai, O. M., \& Long, K. (2009). Physicochemical properties of Kalahari melon seed oil following extractions using solvent and aqueous enzymatic methods.International Journal of Food Science and Technology ,44 (4), 694-701.

Pandey, R., \& Shrivastava, S. L. (2018). Comparative evaluation of rice bran oil obtained with two-step microwave assisted extraction and conventional solvent extraction.Journal of Food Engineering , 218 , 106114.

Phan, V. M., Junyusen, T., Liplap, P., \& Junyusen, P. (2018). Effects of ultrasonication and thermal cooking pretreatments on the extractability and quality of cold press extracted rice bran oil.Journal of Food Process Engineering , 42 (2), e12975.

Pokkanta, P., Sookwong, P., Tanang, M., Setchaiyan, S., Boontakham, P., \& Mahatheeranont, S. (2019). Simultaneous determination of tocols, $\gamma$-oryzanols, phytosterols, squalene, cholecalciferol and phylloquinone in rice bran and vegetable oil samples. Food Chemistry, 271, 630-638.

Psomiadou, E., \& Tsimidou, M. (1999). On the role of squalene in olive oil stability. Journal of Agricultural \& Food Chemistry ,47 (10), 4025.

Qureshi, A. A., Qureshi, N., Hasler-Rapacz, J. O., Weber, F. E., Chaudhary, V., Crenshaw, T. D., Gapor, A., Ong, A. S., Chong, Y. H., \& Peterson, D. (1991). Dietary tocotrienols reduce concentrations of plasma cholesterol, apolipoprotein B, thromboxane B2, and platelet factor 4 in pigs with inherited hyperlipidemias. The American journal of clinical nutrition, 53 (4), 1042S-1046S.

Rovaris, Â. A., Dias, C. O., Da Cunha, I. P., Scaff, R. M. C., de Francisco, A., Petkowicz, C. L. O., \& Amante, E. R. (2012). Chemical composition of solid waste and effect of enzymatic oil extraction on the microstructure of soybean (Glycine max). Industrial Crops and Products , 36 (1), 405-414.

Samaram, S., Mirhosseini, H., Tan, C. P., \& Ghazali, H. M. (2014). Ultrasound-assisted extraction and solvent extraction of papaya seed oil: Crystallization and thermal behavior, saturation degree, color and oxidative stability. Industrial Crops and Products , 52 , 702-708. 
Sengupta, R., \& Bhattacharyya, D. K. (1996). Enzymatic extraction of mustard seed and rice bran. Journal of the American Oil Chemists' Society ,73 (6), 687-692.

Tan, C. X., Chong, G. H., Hamzah, H., \& Ghazali, H. M. (2018). Comparison of subcritical $\mathrm{CO}_{2}$ and ultrasound-assisted aqueous methods with the conventional solvent method in the extraction of avocado oil. The Journal of Supercritical Fluids, 135 , 45-51.

Trevisani Juchen, P., Nolasco Araujo, M., Hamerski, F., Corazza, M. L., \& Pedersen Voll, F. A. (2019). Extraction of parboiled rice bran oil with supercritical $\mathrm{CO}_{2}$ and ethanol as co-solvent: Kinetics and characterization. Industrial Crops and Products ,139 , 111506.

Zhang, S., Zu, Y., Fu, Y., Luo, M., Liu, W., Li, J., \& Efferth, T. (2010). Supercritical carbon dioxide extraction of seed oil from yellow horn (Xanthoceras sorbifolia Bunge.) and its anti-oxidant activity.Bioresource Technology , 101 (7), 2537-2544.

Zigoneanu, I. G., Williams, L., Xu, Z., \& Sabliov, C. M. (2008). Determination of antioxidant components in rice bran oil extracted by microwave-assisted method. Bioresource Technology , 99 (11), 4910-4918.

\section{Hosted file}

Figures doc available at https://authorea.com/users/302059/articles/432006-aqueous-enzymaticextraction-of-oil-from-rice-bran-and-its-quality-evaluation

\section{Hosted file}

Tables .doc available at https://authorea.com/users/302059/articles/432006-aqueous-enzymaticextraction-of-oil-from-rice-bran-and-its-quality-evaluation 